DOI :

\title{
The Globe and the Centennial Calamity: A Staggering Reality to Vet Sustainability
}

\author{
Dr. RizkyWisnoentoro
}

Institut Komunikasidan Bisnis LSPR (LSPR Institute of Communication and Business) , Postgraduate

Programme

\begin{abstract}
Crisis may occur unexpectedly, and - like history - repeatedly. It includes the recurring worldwide calamity triggered by the flu-related virus that is currently hampering the human beings, after a century. This paper proffers to discuss the complex and cluttered phenomena in the vantage point of sustainability that is - in this context - cascaded into human-centered economic development and bio-environment development. Further, this paper envisages the future transformation of the society by learning from the footprints in the vortex of issues lifecycle during the COVID-19 outbreak.
\end{abstract}

KEYWORDS: Sustainability, Sustainable Development, Socio-Economic Development, Strategic Issues Management, Human

Interaction, Values and Culture, COVID-19 Outbreak, Global Pandemics

\section{The Emerging Repetition}

The world we observe today has different measures as compared to the previous decades. No gathering with families and friends would be allowed, and no massive congregation activities for religious or other rituals would be commenced. The coronavirus outbreak (SarsCov2, publicly known as COVID-19 pandemics) has clearly drawn the straight red line that made the current years of 2020 - 2021 to be uniquelydifferent in terms of social, economic, and environment development.

March 1918. This moment has been surpassed in over a century. However, it has regained its prominence amid the current coronavirus outbreak worldwide. As the time flows, a phrase that can be digested from the previous thoughts of Sorokin, Nietzsche, Mark Twain seems to be relevant: History repeats itself.

In the middle of World War I, 1918, the H1N1 influenza emerged. Spain, the neutral country was the only space for the journalist to have the freedom to report the case whereas the other infected nations preferred to apply the restricted filtration in order to remain the morale of the soldiers and the people within the war. The situation that labeled the "1918 Influenza" with the call name of "Spanish flu". The first appearance of the virus in March 1918 in the US was perceived as the seasonal flu, and started its viral spread across several other countries - including Spain - in Europe.

However, the first stage was considered as 'mild', and it was expected to end in August 1918.
James Harris,as written by Dave Roos in History Channel (https://www.history.com/news/spanish-flu-second-wave-resurge nce, originally written on 3 Mar 2020, updated on 22 Dec 2020, accessed on 13 Mar 2021) explained that the global rapid movement of soldiers appeared to be a major catalyst of the viral spread of the disease. Against all expectation, the months of September - November 1918 appeared to be the 'new beginning' of the crisis.

The mutated virus, the lack of medical treatments, and the electrifying shockwave among the humans to face the new deadly crisis had inflicted the death rate to escalate rapidly. The ' $\mathrm{W}$ curve' during the second wave, added by Harris, gave the immense fright to the people, most especially with the atypical spike in the middle of the ' $\mathrm{W}$ '. The crisis then lasted for two years, in three waves (spring, fall and winter 1918), infected 500 million people around the world, and recorded the estimated death rate of 20 million to 50 million victims. In other words, it approximately captured a third of the world's total population at that time.

Howard Markel, as reported by NPR.org (dated May 4, 2020, accessed on 13 March 2021), argued that the method in handling the current COVID-19 outbreak appears to be similar with the 1918 Influenza pandemic. There are the same old-fashioned measures applied to alter the crisis. Most especially, the social distancing to buy the time for the invention of the new vaccines to combat the virus. So the main question here is: how does the current outbreak affect the world? 


\section{The Sustainomics and Triple Bottom Line}

It was intriguing to observe the work of Chakraborty and Maity (2020). They embarked on the ability of Covid-19 to harm the humankind in the sense of endangering the physical wellbeing or global health condition. The frantic spread of the virus may put the people with immune-rheumatologic patience in the matter of prime concern. Thus, it may severely demobilize the global economy. In order to restrict the transmission of the pandemics, countries in the world may have to apply complete lock down measures. Subsequently, it affected the closure of transportations, and also education, sports, commercials, tourism, etc.

In other words, the world we observe today, with more complexities of business, health, and human-related activities as compared to the last century, may plunge deeper into the more hazardous socio-economic vortex. However, in contrary, the lesser activities due to lock down enactment in major countries worldwide may spur better condition of environment on this planet.

With this regard, the discussion in this paper is based on the adoption ofboth the framework ofMunasinghe'sSustainomics (Munasinghe, 2004) and Elkington's conception of Triple Bottom Line economic (Elkington, 2006). Herein, this paper emanates two main areas to be reviewed: human-centered economic development and environment development.

\section{The Global Calamity and the Sequential Waves}

Despite of the similarities in the measures taken to tackle the pandemics, the early stage of the current outbreak appeared to be different with the 1918 flu pandemics. In the previous century, the spread of the outbreak began and occurred in the middle of a massive war.In contrast, the current outbreak appeared to be widely and quickly transmittedaround the globe in the relatively more peaceful condition. It began not in the middle of the intensified world war, but instead, in the middle of the spirit of development.

The current outbreak firstly appeared on the surface in the moment of intensified campaign on sustainable development worldwide, after the enactment of the United Nations' Sustainable Development Goals (Resolution number A/Res/70/1) on 21 October 2015. In other words, in contrary from the previous century, the current outbreak occurred in the middle of the global noble conscience to heal the world and preserve the better lives for future generations.
Yi, Lagniton, et. al. (2020) described that the current COVID-19 is the third outbreak caused by the virus that is highly homologous to the coronavirus $(\mathrm{CoV})$ that caused the previous Severe Acute Respiratory Syndrome (SARS - CoV) originally began in China in the year of 2003, as well as Middle East Respiratory Syndrome (MERS - CoV) in Saudi Arabia in 2012. Thus, on February 11, 2020, the World Health Organization officially named the current virus with SARS $-\mathrm{CoV}-2$, and the associated disease is officially named as CoV Disease - 19 (COVID - 19). This time, the outbreak began in Wuhan, China, and hence transmitted to other countries in a short period of time. The early stage of the spread is shown in the figure below:

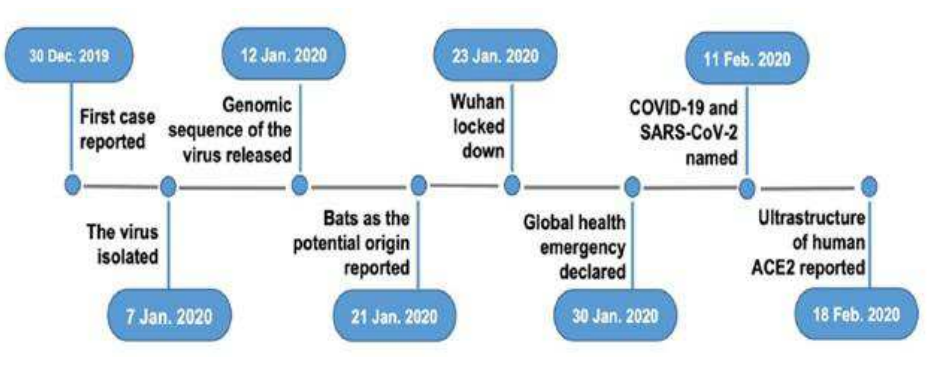

Figure 1: The major events in the early stage of the COVID - 19 outbreak. Source: Yi, Lagniton, et. al. (2020)

As a matter of fact, the current worldwide chart profile seems to be far below the peak of the pandemic in the last century. Speaking about the culmination point, the question is: are we there yet? As compared to the last century's record, this question seems to be relevant. Quasi statistically, the most possible resistant point is 500 million of infected people worldwide, which was the peak number of infected people in 1918 outbreak. In a way, this might still be regarded as a pseudo culmination point. As confirmed cases number still goes uptrend, the current wave may still possibly on its move to reach the ratio of infected people: a third of the total population of the world. Hence, it may start to rebound down and reach the dormant state.

WHO coronavirus (COVID-19) worldwide dashboard (COVID19.who.int, accessed on 12April 2021; 13:00 JKT) showed that there are 646,863 new cases; $134,957,021$ confirmed cases; 2,918,752 deaths; and 669,248,795 vaccine doses administered around the globe.

The American continentappears to be the most affected region with 57,943,462 confirmed case found. Europe came second with $47,528,894$ confirmed cases. South-East Asia is ranked third with 16,177,826 confirmed cases, followed by Eastern Mediterranean on the fourth place with $8,057,550$ confirmed cases. Further, on the fifth and sixth places are Africa with 3,171,006 confirmed cases and Western Pacific with 2,077,538 confirmed cases. 
In the rank of countries that are most affected by COVID-19, the top five list is dominated by those in Americas and Europe. The United States of America appears to be the most affected country with 30,692,226 confirmed cases.Brazil came second with $13,373,174$ confirmed cases. Followed by India on the third place with 13,358,805 confirmed cases. Russia sits in fourth rank with 4,370,617 confirmed cases. The United Kingdom came fifth with 4,241,681 confirmed cases.

The facts found around the United Kingdom have not yet to be brought into and end. Adding the salt into the wound, the world should be prepared for the second wave to swipe out. Taha bin Arif (2021) embarked on a grim reality for the world to anticipate. In the Letter to the Editor of the journal of Infection Control \& Hospital Epidemiology (SHEA -The Society for Healthcare Epidemiology of America), it was mentioned the urgency to prevent the new 'time bomb': more contagious mutated variants of COVID-19.

From the Severe Acute Respiratory Coronavirus Virus 2 (SARS-CoV-2) found in Wuhan, to the new global threat variants: 501.V2 in South Africa and B.1.1.7 in the UK. By December 9, 2020, the 501.V2 strain occupied 62 percent of London, 59 percent of Eastern England, and 43 percent of Southeastern region of England. Furthermore, the computer modelling suggested that the variant of B.1.1.7 strain is 70 percent more transmissible than other SARS-CoV-2 strains. The fear of this new COVID-19 mutated variant had driven countries like Italy, Belgium, France and Netherlands to ban flights to and from United Kingdom. In addition, Saudi Arabia also its commercial flights, and also applying the ban for passengers coming through land and seaport; but it has not been applied to the imports, commodities, and supply chains from countries where the mutated virus has not appeared.

Yet, this fact leads to the incoming of the third wave across Europe - and in the world. Interestingly, 14 days afterwards, the WHO COVID-19 worldwide dashboard showed a rapid incremental happened, mostly in India. The steep uptrend of newly confirmed cases has catapulted this country as the second country that is the most affected by COVID 19 in the world (after the US), with $16,960,172$ confirmed cases. In other words, there is the incremental of 3,601,367 new confirmed case compared with the previous 12 April 2021 data.

The situation in India could be considered as an anomaly, as it mostly occurred after the vaccine rollout in the country. AnooBhuyan wrote for BMJ (https://www.bmj.com/content/372/bmj.n854, accessed on 17 April 2021; 23:08 JKT), that after months of relatively declining figure, the sharp spike of COVID 19 cases happened as India celebrated festivals like Holi, religious functions like the KumbhMela, and with five states involved in elections.

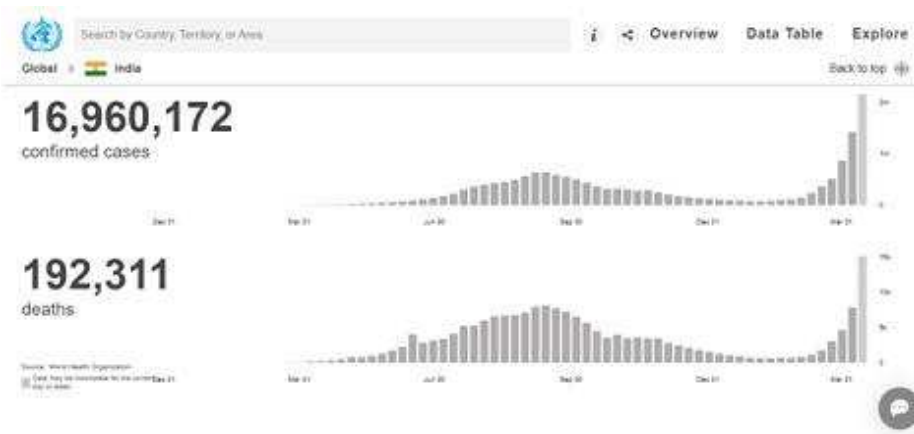

Figure 2: The steep incremental of new cases in India (source: digested fromhttps://covid19.who.int/region/searo/country/in; accessed on 26 April 2021;13:45 (JKT time))

This analysis also cited an important statement from Srinath Reddy, the President of the Public Health Foundation of India who said that there has been a "perfect storm" of reasons for the spike. The rapid upswing in cases, according to Reddy, was inflicted by a confluence of careless crowd behavior, slackening of governmental vigil, and mutations of the virus. Furthermore, Reddy implied that the decline in deaths between October 2020 and January 2021, gave rise to a popular belief that the danger has fully passed, reinforced by overly confident assertions by some experts and politicians that we have attained herd immunity.

Therefore, learning from the USA, United Kingdom, and India, that the COVID-19 outbreak appears to have apocalyptic magnitude throughout the globe. Yet, the search for the root-cause of this problem may recrudesce in the imminent presence of human behavior as the epicenter of the outbreak itself.

\section{Vetting the (Human-Centered)Economic Development: The Unemployment, the Global Extreme Poverty, and the Shift of Work-Consumption Behavior}

Indeed, I believe that it is the deportment of the humans that determines how the future will be performed in reality, apart from any mathematical models. With the presence of COVID-19 outbreak, economic depression seems to be inextricable. Businesses need to keep running in order to avoid the loss. At this point, there is an imminent need for companies to stand strong in the middle of the storm.The social distancing and other health protocols, for instance, has nevertheless jeopardized the long-term economic wellbeing itself.The number of jobless and poverty has been rapidly increased during COVID-19 pandemics in the Asia Pacific region (the first impacted by the outbreak), and in the world at large. International Labour Organization (ILO), in December 2020 and January 2021 released the comprehensive monitoring reports in the region Asia - Pacific and the impact of the outbreak to the world. Both of the comprehensive monitoring reports show the dire impact of the outbreak to the workers in the region and worldwide. Indeed, it also implies the dire impact of COVID - 19 pandemics on the socio-economic development. 
In Asia Pacific, for instance, ILO's Asia Pacific Employment and Social Outlook 2020 (that was also published as the news release on December 15, 2020) revealed an important gap of 81 million jobs lost in 2020, compared to the 2019 profile. It contains 32 million jobs for women and 49 million jobs for men. Before 2020, employment in the region followed a steady upward trend, with annual employment growth rates of $0.7-0.9$ percent, which was disrupted sharply by the crisis. Further, the report shows that wages in many countries within this region have stagnated or declined during the COVID-19 crisis. During the outbreak, especially in the first three quarters of 2020, the overall labour income is estimated to have declined by as much as 9.9 percent, which is equivalent to a 3.4 percent loss in gross domestic product. With that said, the report also cited World Bank that estimates the additional 22 million to 25.4 million of working poor (living on less than $\$ 1.90$ a day).

Thus, it contributes to the total number of working poor people in 2020 to an estimated 94-98 million. The breakdown by sub region is an additional 4 million to 5.6 million working poor in East Asia and South-East Asia and the Pacific combined and 17.9 million to 19.8 million in South Asia.

In a wider view, the massive global spread of the outbreak also impacts the world at large. ILO monitoring report (2021) revealed that up to January 2021 when the report took place, there are 93 percent of workers residing in countries with workplace closure measures. Interestingly, the report also revealed that within countries, more geographically targeted and sector-specific measures have gradually become the norm. Yet, this condition is still affecting 77 percent of workers at the beginning of 2021 (which is nearly reaching the peak of 85 percent reached in late July 2020). Further, the figure below shows the dire phenomena of employment and labour income loss due to COVID-19 outbreak.

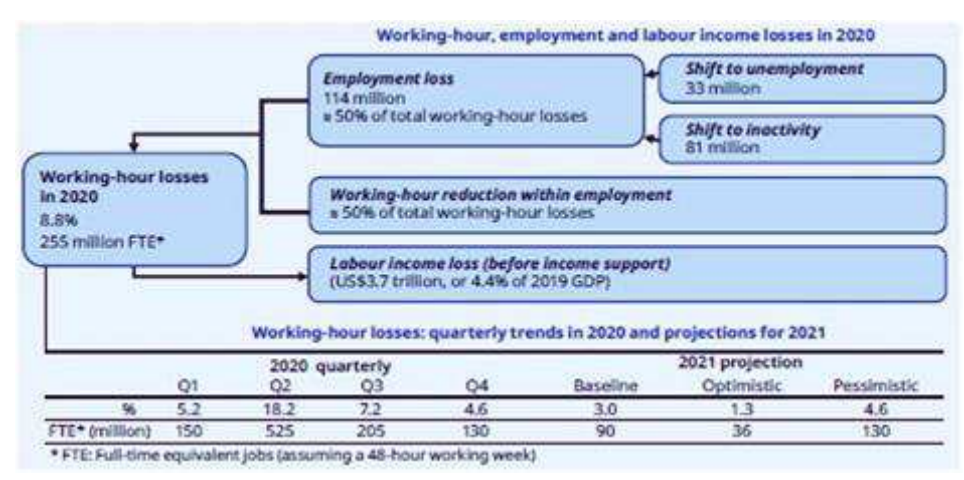

Figure 3: Working-hour, employment and labour income losses in 2020; and the projection for 2021 (source: ILO Monitor, 25 January 2021)
The report shows that 255 million jobs have been lost due to the global pandemics. It comprises the 114 million employment loss that are shifted into unemployment (33 million) and inactivity (81 million); as well as 50 percent of total working hour losses. With that said, the worldwide labours also suffered a heavy loss totaling of US\$ 3.7 trillion, or equal with 4.4 percent of 2019 GDP (before income support). In this report, it was highlighted that employment losses were higher for women (5.0 percent) than for men, and also for young workers (8.7 percent) than for older workers. This situation, according to the report, is approximately four times greater than during the global financial crisis in 2009.

In the general projection of 2021, the figure implies anexpectationof a better condition. However, the dark shadow of dire impact does exist. Even in the optimistic projection, it is still expected the loss of 36 million jobs worldwide. Not to mention, the pessimistic projection that estimates the loss of 130 million jobs. As a matter of fact, it is inevitably related with the increasing poverty.

Furthermore, the study conducted by Blustein, et.al. (2020) seemed to be concurred with the facts elaborated in the reports of ILO. The discussion in the paper found that COVID-19 outbreak has exposed and exacerbated existing inequities in the labor market. Millions of workers (especially in the US) are suffered from having precarious jobs, uncertainty, as well as vulnerability to advocate their needs including the reduced power and access to basic benefits, wages, or privileges. Thus, people with precarious work experience chronic stress and uncertainty, putting them at risk for mental health, physical, and relational problems. Direct cash, in this instance, appears to be popular as an efficient approach for governmental and non-profit interventions to help people in poverty.

On October 7, 2020, David Malpass, the President of World Bank Group, expressed that the pandemic and global recession may cause over 1.4 percent of the world's population to fall into extreme poverty (https:/www.worldbank.org/en/news/press-release/2020/10/07/co vid-19-to-add-as-many-as-150-million-extreme-poor-by-2021 (accessed on 28 April 2021; 13:49 JKT)). Further, in order to reverse setback to development and poverty reduction, Malpass urged countries to prepare for a different economy post-COVID, by allowing capital, labour, skills, and innovation to move into new businesses and sectors.

This statement was released in accordance with the World Bank's revelation of the sorrowful fact that the global extreme poverty (living below $\$ 1.90$ a day) greatly rose in 2020 for the first time in over 20 years. 
It was ultimately inflicted by the disruption of the COVID-19 pandemic that compounds the forces of conflict and climate change, which were already slowing poverty reduction progress. As a matter of fact, the convulsion of the outbreak on the globe is estimated to push 88 million to 115 million people into extreme poverty in 2020. Thus, the total rising is projected to reach the number of 150 million people in the world to suffer the extreme poverty by 2021, depending on the severity of the economic contraction.As the World Bank revealed, middle economic countries will be the most affected by the storm of new poverty rise. The data showed that eight of ten 'new poor' will be in middle-income countries.

Subsequently, with the jobs and income plunged into the calamity, the middle-income business sector is one of those entrapped in the middle of the apocalyptic crisis. In this context, the small-medium enterprises (SMEs) are among the vulnerable field actors whoare heavily damaged by the outbreak. Bartik, Bertrand, et. al., (2020) emanated several important points from their survey of more than 5,800 small businesses between March 28 and April 4, 2020, in order to explore the impact of COVID-19 on small businesses.

Besides the findings that mass layoffs and closures had already occurred just a few weeks into the crisis, the survey also found thatthe risk of closure was negatively associated with the expected length of the crisis. In this case, businesses had widely varying beliefs about the likely duration of the outbreak. Moreover, the survey found miserable fact about how fragile many small businesses are in terms of financial performance. For instance, the median business with more than $\$ 10,000$ in monthly expenses had only about 2 weeks of cash on hand. Furthermore, the majority of SMEs planned to seek funding aid but have to face many anticipated problems with accessing the program, such as bureaucratic hassles and difficulties establishing eligibility.

With this regard, poverty and mental health appear to be a challenging discussion amid the outbreak. Not only that it is related with unemployment, the mental health also appears to jeopardize workers' performance at work.Let alone in the US, Kniffin, et.al (2020) emanated that the closure of many types of business including travel, hospitality, sports, and entertainment, drove tens of millions of people to file new unemployment claims. Subsequently, financial deprivation of losing income brought a serious concern of mental health (including depression, anxiety, and physical ailments). Henceforth, it triggered a spiral of adversity that affects the entire family.

Another trend emerged to the surface: Work From Home (WFH) or Mandatory Work From Home (MWFH). In many countries, it seems to moderate the triangle of needs: the compulsory isolation, curfew, and lockdown measures applied by the government; the need for businesses to stay productive; and the need for workers to still earn income (still become actively employed).Kniffin, et.al. (2020) highlighted that in the early stage of the pandemics, approximately one-half of the companies had 80 percent of their employees working from home, and estimated a substantial long-term increases for remote work after the pandemics. Indeed, the term 'remote work' implies a broader meaning, such as Work From Anywhere (WFA).

For several types of jobs that may require lesser human interaction, this mode of work would probablybe suitable and the favorite of choice. However, in general, some hassles may appear including the space for work and the need to re-arrange other space in the family as well (especially for workers who are not living alone). Notwithstanding, the 'new' set of virtual work habit begins to take place. The 'Virtual Teams' and 'Virtual Leadership Management' become the new reality to deal with.Interestingly, this new habit does not only contribute to the unemployment and layoff. It also impacts the growth in presenteeism.

For example, the paper highlighted recent studies in Poland and Australia where approximately 20 percent of people diagnosed with flu did not take sick leave. Moreover, the virtual habit may bring another vexatious problem that there are two types of people who attend work when ill. On the one hand, there are people who are essentially feel forced to attend due to heavy job demands, including excessive workload, understaffing, and required overtime. On the other hand, there are people who are committed to their organization and/or highly engaged in their work.

In other words, along with the adaptation to the new habit of 'virtual work', there are several crucial consequences to be addressed. A predicament which, to a further extent, may also happen in any other countries. Forbes magazine's contributor Chris Westfall (2020), revealed a dire situation related with mental health and remote work among employees at the early stage of the outbreak, and still relevant up to the moment this paper is written

(https://www.forbes.com/sites/chriswestfall/2020/10/08/mental-he alth-leadership-survey-reveals-80-of-remote-workers-would-quitheir-jobs-for-this/?sh=17bc7f243a0f (29 March 2021: 11:00 am $\mathrm{Jkt})$ ).

Citing the survey of 1000 Americans conducted by TELUS International, Forbes embarked on the facts around remote work in pandemics. 80 percent of workers would consider quitting their current position for a job that focused more on employees' mental health. 
The data also showed a complication of psychological problems among remote workers and leaders including stresses, anxiety and uncertainty. 75 percent of U.S. workers have struggled at work due to anxiety caused by the COVID-19 pandemic and other recent world events. Further, the survey embarked on some more alarming agony. 4 out of 5 workers found it hard to 'shut off' in the evenings. Majority (more than a half) of the respondents have taken a "mental health day" since they started working from home, due to the pandemic.

Also, another solid argument that shows the concern on mental health came from 97 percent of the respondent who stated that vacation days while working from home are important for "recharging". Moreover, another dismaying fact was also found that a half of the respondents cite that their sleep patterns have been interrupted due to COVID-19; and 45 percent of respondents stated that they feel less healthy mentally while working from home. With this regard, the WFH or MWFH that appeared to be the solution at the beginning, may also bring a set of calamitous consequences among the workers and leaders.

In another vantage point, the dire impact on human-centered socio-economic also implies the fact that the human behavior begins to shift. The economic slowdown that leads to the crisis, and the increasing number of unemployment and poverty converge into a condition where humans should accept the reality. Which means, it is the set of 'new' values, norms, habits, traditions, and hence manifested in the 'new' cultural artefacts. The social distancing measures, for instance,as well as the other protocols done during the lockdown will emergeinto becomingthe new set of habits and traditionsto still be actively generating income in the relatively reclusive boundaries.Also, the urgency of regulations to wear face mask will potentially lead to the changing habit and other cultural artefacts such as fashion trend.

Therefore,COVID-19 outbreak also brings in an urgent change of consumer behavior to be anticipated. At this point, the turmoil in global pandemics appears to gear up the transition among humans that would affect the massive new trend of consumption. As digested in Cohen (2020), the practical outcome is that the customarily face-to-face activities move to virtual platforms. People are accustomed to utilize online platforms for their businesses, education, or other social activities. "As is frequently the case in the aftermath of disasters, we will quickly forget 'how things used to be'." (Cohen, 2020).

In contrary, there will also be a strenuous persuasion to return the life back to the previous 'normal' condition. In this matter, in Cohen's viewpoint, COVID-19 is the opportunity to reduce the consumption of large volumes of energy and material throughput.
However, the social distancing imperatives that are actually aimed to reduce the virus transmission will reinforce people's adherence to individualized instead of the public and shared model of consumption.

As a matter of fact, apart from the contradiction, the pandemics has brought in a shift of habit in buying and selling consumer goods. Further, it may also impact the orientation of buying properties, livestock, and other fundamental primary needs. Thus, it will as well impact the pattern of consuming the financial instruments such as banking products, insurance, and even stocks or bonds. Further, the process of intergenerational internalization will start the new set of norms and values in the social lifecycle. The old values about the beliefs and norms may exist, but along with the new ambience of habit and tradition immersed by the results of COVID-19 disruption, in addition to the previous digital disruption before the pandemics.

Subsequently, it comes to light that the issues among consumers and workers are likely to be shifted. For example, the virtual style of work, managing the organization, and in the consumption habit take shape to become the bottom line for the future digital innovation. Although it would still be arguable to sustain for academic activities (especially for children in primary level).

This has resulted in another eyebrow raising fact, in lieu of the major economic downturn in the globe. The pandemics is a windfall for digital-based companies. They have clinched an astonishing financial performance at large. Jordan Novet of $\mathrm{CNBC}$, for instance, highlighted the tremendous earnings of Zoom, a provider of online meeting platform (https://www.cnbc.com/2021/03/01/zoom-zm-earnings-q4-2021.h tml (accessed on 26 March 2021; 12:05 pm Jakarta)). It was reported that Zoom shares rose 11 percent after the company reported fourth-quarter earnings, showing sequential revenue growth. The company's revenue was reported to grow 369 percent (year over year) in the fourth quarter that ended on January 31, 2021. Forbes analyzed that people began to use Zoom more heavily as the Covid-19 virus emerged in China, and the use of this platform began to be mushrooming after the World Health Organization decided COVID-19 as a pandemic in early 2020.

Thus, Forbes put a special highlight that the company ended the quarter with $\$ 4.24$ billion in cash, cash equivalents and marketable securities. It is a solid uptrend compared to $\$ 1.87$ billion cash Zoom earned in the previous quarter. The company, then, expected 42 percent revenue growth for the fiscal year ahead. Meanwhile, Alphabet Inc. (NASDAQ: GOOG, GOOGL), the parent company of Google and YouTube, announced their 2020 financial performance that was ended on December 31, 2020 . 
The official press/public release document showed that the company harvested a triumph of $\$ 56.9$ billion revenue, which was driven by Search and YouTube. Further, Google Cloud revenues were $\$ 13.1$ billion for 2020. Moreover, analyzed by Jordan Novet and Jennifer Elias of CNBC, Alphabet's revenue grew 23 percent on an annualized basis in the quarter, stronger than their performance in Q4 of the previous year, which came in at 17 percenthttps://www.cnbc.com/2021/02/02/alphabet-googl-earning s-q4-2020.html (accessed on 29 April 2021; 15:38 JKT). The company also recorded 22 percent of incremental in advertising revenue for the fourth quarter that came out to $\$ 46.20$ billion, compared to $\$ 37.93$ billion in $\mathrm{Q} 4$ of the previous year. This report indicated a monumental comeback after they were plunged for 8 percent annualized advertising revenue decline from Q2, at the early stage of COVID-19 outbreak.

Another interesting data came from Alphabet's YouTube advertising earnings of $\$ 6.89$ billion in Q4. It is 46 percent higher compared to their $\$ 4.72$ billion earnings in the same quarter of the previous year. Indeed, this phenomenon confirms the emerging trend of virtual/online life induced by the outbreak. It is also shown in other particular facts that YouTube recorded strong growth in "direct-response" ads. In this platform, consumers are triggered to take immediate action (i.e. download an app or buy something) from an e-commerce site.

Nevertheless, it is compelling to learn that this business was heavily grown up during the outbreak. Philipp Schindler, Google's Chief Business Officer explained that the incremental of YouTube advertisement earnings was inherent with the increasing number of viewers and also the longer time spent watching videos. The company currently reaches more 18-49 year olds than all linear TV networks combined. Further, it is also intriguing to digest Schindler's explanation that YouTube 'direct-response' advertisement business was considered as non-existent three years ago. Yet, it has become one of the largest and fastest-growing advertisement offerings on You Tube.

Indeed, it is tantalizing to observe the stellar growth of the tech-based companies in 2020. In other words, it shows how COVID-19 outbreak inflict the shifting behavior of the public at large. This is the unique phenomenon with two contrast conditions at the same time. On the one hand, the world is facing the dire and detrimental impacts on economics such as unemployment, extreme poverty, followed by the agonizing concerns on the mental health of the public at large (including the workers and the jobless). In contrast, on the other hand, the shift into virtual habit seems to be imminent. Besieged under restrictions and constraints that hinder the 'normal' direct human interaction, the people seemed to hold tightly on the utilization of internet to find consonance out of the dissonance.

\section{Vetting the Bio-Environment Development}

Interestingly, Chakraborty and Maity (2020) emanated the idea that the restricted movement on the planet due to lock down had resulted in such an outstanding impact on the global environment. The lesser number of vehicles on the road, for instance, resulted in almost zero emission of green-house gases. Also, the non-functioning industries resulted in the large-extent decrease of industrial waste emission. The use of fossil fuels and other conventional energy sources has also been considerably lowered due to the lesser demand of power in industries. Nevertheless, the pollution level in tourist spots has been greatly reduced. In other words, the global pandemics have shown a contrast impact on environment. As it provides the chance for the planet to revive significantly.

Embarking on the similar tone, Zambrano-Monseratte, Ruano, and Sanchez-Alcalde (2020) highlighted the indirect effects of COVID-19 outbreak to the global environment. There are several positive effects to the world. First, the quarantine incites the decreased of NO2 and the hazardous Particular Matter 2.5 (PM 2.5). It generates air quality improvement, most especially in Wuhan (China), as well as in the first cities to implement strict quarantine measures in Europe (Rome, Madrid, and Paris). Second, clean beaches. The study recorded the positive change in the appearance of many beaches in the world, such as Acapulco (Mexico), Barcelona (Spain), and Salinas (Equador). It is mainly caused by lack of tourists, as a result of social distancing measures. Third, the reduction of environmental noise level. Since the enactment of lock down and quarantine measures in major parts of the globe, there has been a considerable drop of unwanted sound caused by anthropogenic activities (commercial / industrial activities), engine/vehicles, or melodies at high volume. The nearly total cessation of commercial activities, as well as the use of public transportation, for instance, have caused the important reduction of discomfort due to the environmental noise.

However, the depletion of greenhouse gas emission level or the discomfort environmental noise in relatively a short period of time - due to the pandemics - would not be a good sign to sustain the future condition if there is no establishment of specific system to mitigate the excessive behavior in the future. The work of Zambrano-Monseratte, Ruano, and Sanchez-Alcalde (2020) also embarked on the negative impacts of the COVID-19 outbreak to the global environment. First, the online habit during quarantine has increased the waste. The shifting consumer habit to online shopping, for instance, has increased the organic household waste. Further, the packaging of the online shipped food has increased the inorganic waste worldwide. Not to mention, the medical waste is also on the rise during the pandemics. In Wuhan alone, as discussed in the paper, hospitals produced an average of 240 metric tons of medical waste during the outbreak. 
It shows a significant incremental compared to the average of fewer than 50 tons prior to the pandemics. In other countries such as the USA, the paper also embarked on the increasing level of garbage from personal protective equipment such as masks and gloves.

\section{So the important discussion here is: How long would this crisis happen? And how should we anticipate the aftermath?}

\section{Envisage of the Aftermath Transformation: Humans as the Epicenter of Post-COVID Development}

Indeed, it is intriguing to find out that both economic and environment dimensions of the development address a similar bottom line: human is the epicenter of the development (for good or bad impact), although the crisis events may presumably strike from other preceding factors. With this regard, referring back to the original thoughts of Pitirim Sorokin in 1927 (as described in Richard L. Simpson, 1953) seems to be relevant, especially as the guidance to understand the social phenomena. In this case, it includes the demonstrationof the analysis on quantified social data to explain social mobility; and also when - in my interpretation he moved to a qualitative essence to understand the types of culture integration in 1941: Sensate, Ideational, and Idealistic categories.

In reflection to the current context, the global pandemics incited various vertical and horizontal mobility. On the one hand, there are people who fall down from the top social status to the bottom layer. It is mostly inflicted by the repercussion of economic crisis that entrapped people to lose their jobs or to plunge in heavy losses in their business profitability. On the other hand, the pandemics also brought in another reality that some other people may successfully climb the social ladder with their triumph in technology inventions. Meanwhile, on sideways, the horizontal mobility also occurred. There are several other people who decided to switch their mindset and try to ride the wave of digitalization in order to sustain their lives. This practically happened in various range from the SME level up to the large-scale businesses.

At this point, I concur with Sorokin's thought when he proffered that, historically, high mobility has been associated with versatility, invention, and discovery; but also with cynicism, social isolation of the individual, skepticism, moral disintegration, and suicide. Indeed, the history is repeated (again). The COVID-19 outbreak expedites both vertical and horizontal mobility at relatively the same time, under the same circumstances. In this instance, the history may be repeated, but not at the same form as it was, before the outbreak. As Sorokin observed in 1942 that society "is never the same as the one that existed before the calamity. For good or ill, calamities are unquestionably the supreme disruptors and transformers of social organization and institutions" (Sorokin, 1942, in Cohen, 2020).
Therefore, looking from the vantage point of interpretive paradigm, there has been a chaotic collision in understanding and constructingthe reality. On the one side, invention and discovery emerge to be the media darling and hence followed with the smoldering record of fantastic financial performance in their businesses. Yet, they even provide the new means of computer-mediated communication: social media. It provides the new reality to solve the social relationship problem caused by isolation, distancing and lockdown. Notwithstanding, on the other side, the isolation itself has brought psychological agony and dissonance that tend to abuse the natural human needs for direct socialization and interaction. A phenomenon where, in Sorokin's terms, the bodily sensation (Sensate) collides with the hope and faith (Ideational) that the pandemics will soon be over (whereas, featured in major mainstream media, the 'end' seems to be far away).

In this instance, Idealistic mentality that combines the two polar virtues may also fail to construct the reality. Their physical senses, for example, capture a reality that buildings stand still, and other natural signs that refer to the normal condition (no sense of hazardous crisis). However, their minds keep being internalized by the media and other means of communications that the war against the nanometer-sized enemies is still far from end. Driven by the natural desire to exile from the dissonance (isolation - distancing) and hence to seek for the convenience and consonance, I could comprehend the magnitude of people in India to gather again whenever possible; that caused the sharp spike in the chart of infected people after the vaccination. As a matter of fact, this may also occur in any other countries. A situation that is approximately (but not definitely) similar to the second wave of the 1918 pandemic when the total number of infected people were highly escalated.

Not to mention, the collision of perceived realities among the people who fell down from the top layer into the bottom layer of the society. People in this condition lose their pride and other social attributions in a short time. In addition, those who put an endeavor to switch their businesses or lifestyles are also living in jeopardy to understand the new realities they have to face. Meanwhile, those who successfully climb up the social ladder with their technology inventions may also be haunted by the nagging question: will this new wealth sustain?

In other words, the tug-of-war seems to be imminent: the surge of digitalization wave that signifies the panache of innovative and progressive future life, against the desire to get back to the perceived reality of 'normal' life before it was deteriorated by the precipitous COVID-19 outbreak. Subsequently, it would further intrigue the vortex of issues life cycle at large, that may be recurring in centennial pandemics. 
In 1985, Crable and Vibbert(as described in Chong (2006)) stated that an issue is created when one or more human agents attaches significance to a situation of perceived 'problem'. The year of 2020 and 2021 are academically intriguing to delve the cycle of the issues in the public. In the beginning, people are still shocked by the viral information about the situation in Wuhan. Then, the next stage was the domino effect of lockdown policies applied by many countries in nearly all regions around the globe. The issue of medicine was overwhelmed by the exposure of the number of new cases that keeps increasing in the world. Thus, the issue went on to the search of the cure. The public discourse about vaccine, then, appears to be one of the most anticipated issue by both the media and the public at large, including the authorities. The vaccine development seems to extend a hope for the better condition. However, the side-bar of the public issue seemed to be far from end with the mutated virus exposed in several areas.

So, another question that keeps nagging is: how long would this crisis last? In reflection with Sorokin's thoughts as well as Crable and Vibbert in the context of the pandemics' issues life cycle, I would conjecture that authorities, companies and also the public at large should make a firm trajectory to anticipate the worsen situation within approximately two years (in short term, that has already been started in 2019-2020, similar to the duration of 1918 outbreak), up to the next two decades (medium term), and over a century for a long term anticipation. Facing this condition, more institutions would be tempted to undergo the tight money policy, layoffs, or other similar options. Worldwide companies and their publics, insofar have I learned, are sailing in the same stormy water.

At the beginning of this paper, it was understood that the history implies similar pandemics to recur in the century-long interval. Therefore, it is relevant to foresee another change within the next century. However, why should the public also be focused in the nexttwo-decade medium term change? First, the 1918 pandemics provided an important lesson that the virus will never completely be vanished. The vantage point of environment sustainability has brought a valuable thought that people should always anticipate its ability to mutate faster and sooner than in the expected century-long interval.

Second, in the next two decades, it is logical to expect that the current young-aged 'COVID survivors' will lead the new mindset and habit that may converge into the new set of culture in the future lives of human beings. They will become the main opinion leaders in the public to share the new habits to adapt with the COVID-19 or any similar crisis to it. In other words, it is logical to expect the global shift of mindset (that reflect the people's values and norms) within this period of time. Which shall be resulted in over a century that the society will start to internalize the new set of culture and its artefacts to live side-by-side with the haunt of coronavirus (or the mutated ones).
In this instance, the tug-of-war began to gain attention among various layers of the public. Will the digital mindset last in the aftermath? Or will everything go back to 'normal' as in the condition prior to the outbreak? With regards to the human-centered sustainable development, there are at least two important lessons that we could learn from the outbreak:

\section{The surge of digital wave vs the desire to revert back to 'normal' condition prior to the outbreak.}

With the considerably mild impact on environment, COVID - 19 outbreak becomes essential in the context of human-centered or socio-economic development. The public observe two contrast phenomena at the same time: the unemployment that inflicts extreme poverty and mental health predicaments, and the rise of the digital-based activities.

On the one hand, the internet and virtual world take shape as the cavity for humans to be amused byan interim sanctuary amid the anxious challenge of global restriction and lockdown measures to block the virus transmission. The use of social media and online meeting platforms seemed to be increased essentially, and we could track the footprints from the momentous rise of financial performance in several tech-based corporations. Subsequently, in foreseeable future, it is logical to expect the rise of digital-related job creations, as well as the other functional jobs that indulge people at home or other services that help people to anticipate the future. At the same time, it also reflects the imminent need to preempt the digital reputation management.

The increasing usage of social media, for instance, may be resulted in a severe setback for those who are unable to ride the wave of issues. With the great reduction of direct face-to-face communication, the discussion in new media (social media) may step backwards when emotion, anxiety, and other mental health problems are deeply involved. The level of psychological sensitivity may grow, and people could easily offend or be offended. Thus, defamation and slander cases may increase at the same time the income of the giant tech companies thrive. Doorley\& Garcia (2007, p. 391)highlighted about the immense need of Public Relations to anticipate the development of new media \& technology. Yet, the outbreak expedites the quantum leap of tech-based interaction.

However, on the other hand, the constant reliance on virtual work appears to hinder the people from their original life. The discussion in previous parts of this paper showed how mental health blooms as the ultimate concern for workers and the unemployed publics. The dissonance in a person's life may hamper the entire family.In short, the side effect of the pandemics would possible to go viral at the same velocity with the spread of the virus itself. 
At work, implementing Work From Home or Work From Anywhere (remote work) constantly in a long and winding outbreak makes people suffer from various mental health. In some cases, sick leaves are ignored and employees are bound to struggle with (or enslaved by) their unlimited work schedule. Not to mention, the dire facts that hamper the unemployed people because of the outbreak. Facing the extreme poverty threat, people are getting more anxious and uncertain that trigger more psychological damage at alarming level.

Adding the salt into the wound, the new virtual habit and consumption still have to conform to the environment. Despite of the outstanding record of COVID-19 on the healing of planet Earth, the shifting of consumption pattern into virtual habit may burden the environment. The abovementioned discussion showed that virtual habit contributes to the increased domestic/household waste, inorganic waste (the packaging of the online shipped food), as well as medical waste.

With that said, the tug-of-war seemed to be imminent between the desire to return back to the previous 'normal' life, and the spirit to anticipate the new digital-based future. Apart from the conflict of mindset, there are at least three main fundamentals to sustain the calamity as highlighted in Wisnoentoro (2020): adaptability, agility, and networking/partnership. Adaptability enables people to fit themselves in any of the changes emerge from the outbreak, as a person, group, or organization/companies. Ranging from the habit, up to the set of conducts/governance along with its artefacts/products. Agility would enhance intelligence, vigor, and quick-moving of the people or organizations/companies in riding the wave of any crisis; especially during the pandemics. A quick-move to shift the strategy and action, in this matter, would be such a life-and-death moment to sustain the calamity. Lastly, the partnership would help share the burden and - at the same time -energy to stand in the middle of uncertainty and anxiety in the pandemics.

\section{Envisage on the future transformation: lessons learned from the vortex of issues life cycleduring pandemics}

In the above mentioned discussion, I was intrigued by the thoughts of Sorokin that society is never the same as the one that existed before the calamity (Sorokin in 1942, as cited in Cohen, 2020). This implies a forward looking of the transformation of a society prior, during, and after the calamity. Not to mention the collision of perceived reality between the senses and hope among humans that makes the outbreak take shape to become an ultimate issue worldwide. Also, in the nature of human beings to move from inconvenience (dissonance) to find the convenient (consonance) condition. However, the sudden outbreak has hindered the people from being able to anticipate the future.
Hence, it resulted in the entrapment of uncertainty that incites anxiety and worsen mental health problem. In short, the enigma of COVID - 19 pandemics would converge into the immense need to envisage the vortex of the issues life cycle and the crisis itself. By detecting the current footprint, we would be able to anticipate the future calamity when it recur. With this regard, understanding issues life cycle seems to be essential.Dougall (2008) wrote for Insittute of Public Relations: "issues are commonly described as having a lifecycle comprising five stages - early, emerging, current, crisis, and dormant" https://instituteforpr.org/issues-management/ (accessed on 30 April 2021; 10:21 JKT).

In the context of COVID-19, the outbreak moved linear from an early stage in Wuhan, and emerge as a public issue when other areas were also infected. It became the current issue when the WHO began to jump into the case. Henceforth, it turned out to be a worldwide crisis when countries began to apply various measures including the lockdown that severely impacted to the socio-economic development. Up to the moment when this paper is written, it appears that the world is still in the crisis and not yet reaching the dormant stage.

However, Jaques (2007) emphasized Bigelow et. al. (1993): "issues do not necessarily follow a linear, sequential path, but instead follow paths that reflect the intensity and diversity of the values and interests stakeholders bring to an issue and the complexity of the interaction among the ... factors." Therefore, in this instance, from the vantage point of public at large, the issue of outbreak quickly jumped to emerging case (in the news about Wuhan), then reached the worldwide crisis stage in a relatively short term, and hence stayed in this level (not yet reaching the dormant stage). Notwithstanding, the ubiquitous publicity about the updates on the number of infection cases in various countries may drive the COVID-19 into dormant. At some point, the ubiquity may overwhelm the public largely, and it may gradually shift the public's mindset to foresee the ideas of hope for the post-COVID condition.

In other words, encumbered by abundance and cluttered messages about the dangerous and threatening COVID updates, the public may be saturated. At this point, the rise of post-COVID oriented discourses would begin, such as: what next and what would we do in the aftermath?

The figure 4 above shows the footprint of how issues may turn into vortex in the long run. It begins with the sudden outbreak that emerged to become a global calamity, which incited the anomie or massive uncertainty and the collision between the reality and the idea or hope. In other words, it was such a shocking moment. New measures were taken immediately, as what the accountable authorities should naturally do to respond the crisis, in various level ranging from municipality, city, state/province, up to the national and international level. 


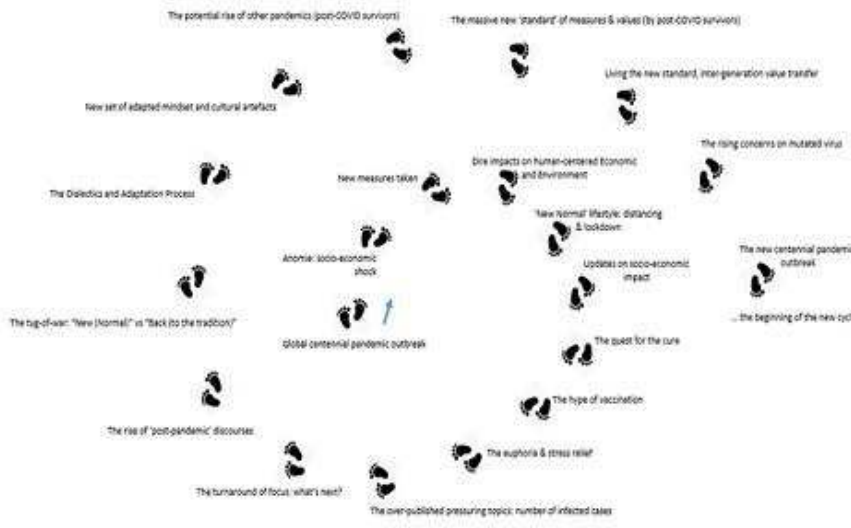

Figure 4: Envisage about the future transformation of the society after the calamity, based on the footprint in the vortex of issues lifecyclewithin the recurring global centennial pandemics

However, the dire impacts on human-centered economic and environment seemed to be inevitable. Social mobility happened accordingly, with the intriguing contrast between extreme poverty on the one side and the raise of income generation in digital stream on the other side. Thus, the measures are tightened up to become the habit and tradition of 'new normal'. Distancing and lockdown, at this stage, are the common issue surrounding the public followed by other subsequent actions such as WFH / remote work and other virtual activities (including the virtual buying and selling of goods).

Now that humans become the major impacted stakeholder of the outbreak, the media keeps on constantly updating the impact on socio-economic matters. Under siege of anxiety, the quest for the cure started to fulfill the air. Beside medicines, vaccination appears to be the perceived solution, especially from the official view of the WHO as seen in the worldwide dashboard of COVID-19. Yet it feeds the collective conscience among the publics in the drought of the cure. The hype of vaccination may bring relief to ease the public stresses.

However, some parts of the public may be trapped in euphoria and hence loosen the tight measures that is possible to cause the setback. Notwithstanding, it seems to inject_a hope in public perception. Gradually but surely, the increased hope is inherent with the saturation of the public on any staggering news about COVID-outbreak.In other words, the number of cases overwhelm the public. Henceforth, it leads to the current condition: the turnaround of focus. Some parts of the public may induce the initiation to shift the issue into a more forward-looking vantage point (i.e. what's next after COVID?). This leads to the stronger public discourses on post-pandemic trajectory. This is where the tug-of-war takes place, as the publics are torn into two different mainstreams: surge the digitalization wave, or back to the normal condition before the pandemics.
In the future, the tug-of-war would bring the process of dialectics and adaptation. Thus, the new set of mindset would take place that breeds the new cultural artefacts. However, with regards to the bio-environmental fact that the virus keeps on mutating, the post-COVID survivors would constantly lead the public opinion and squawk on the potential rise of the other pandemics. Therefore, the massive adaptation processes would converge into the new standard of measures and values to live in. With this regard, the academic prophecy is highly plausible to occur in reality: the world would transform into the society with new set of values, norms, habits, tradition, and other cultural artefacts. Learning from the 2019-2021 pandemics, as well as the 1918 outbreak, the future society would (and should) be able to anticipate the other calamity, although the virus is predicted to mutate repeatedly.

In a nutshell, I tend to be agree that the history does repeat itself. This paper envisagesabout the future transformation of the society after the calamityas an attempt to digest how it would recur in the future, based on the footprints detected in the current vortex of issues lifecycle withinthe outbreak.

\section{Conclusion}

This paper proffers to vet how humans sustain the calamity when history repeats itself. Throughout the centuries, at least from the occurrence of 1918 pandemics, followed by the current COVID-19 outbreak, the lessons converge into one conclusion: human being is the epicenter of the entire phenomena on the planet. The pandemics, in this case, happened with a great challenge for humans. Along with the predicaments, came the valuable lessons to learn, ranging from the human-centered economic development (socio-economic factors), as well as the bio-environment development. As the digest of the lessons learned, this paper envisages the plausible future transformation of the society to anticipate the repeated pandemics, by learning from the footprints of the vortex in issues lifecycle during the current outbreak.

All in all, with hardship comes ease, and hence it leads to tranquility. Indeed, I believe that there will always be a positive way to view every phenomenon on the planet. The concept of sustainability intrigues the forward-lookingamong humans to be adaptable, agile, and develop strong partnership and network to sustain the calamity. The ability of the current generation to live the world today will breed valuable lessons for the future generations to sustain the world in their time.

\section{List of Books, and Manuscripts/Articles for Further Readings}

Arif, T. Bin. (2020). Letter to the Editor 501.V2 and B.1.1.7 variants of COVID-19: A new time-bomb in the making? Infection Control and Hospital Epidemiology, 2019, 1-2. https://doi.org/10.1017/ice.2020.1434 
Bartik, A. W., Bertrand, M., Cullen, Z., Glaeser, E. L., Luca, M., \& Stanton, C. (2020). The impact of COVID-19 on small business outcomes and expectations. Proceedings of the National Academy of Sciences of the United States of America, 117(30), 17656-17666. https://doi.org/10.1073/pnas.2006991117

Bhuyan, A. (2021). Covid-19: India sees new spike in cases despite vaccine rollout. BMJ 2021. https://doi.org/10.1136/bmj.n854

Blustein, D. L., Duffy, R., Ferreira, J.A., Cohen-Scali, V., Cinamon, R.G., \& Allan, B.A. (2020). Unemployment in the Time of COVID-19: A Research Agenda. Journal of Vocational Behavior, $\quad 119 \quad$ (2020)

https://doi.org/10.1016/j.jvb.2020.103436

Chakraborty, I., \&Maity, P. (2020). COVID-19 outbreak: Migration, effects on society, global environment and prevention. Science of the Total Environment, 728, 138882. https://doi.org/10.1016/j.scitotenv.2020.138882

Chong, Mark. (2006). The Importance of Issues Management in International Mergers and Acquisitions. Research Collection Lee Kong Chian School of Business at Institutional Knowledge at Singapore Management University. https://link.library.smu.edu.sg/lkcsb_research/2483.

Cohen, M. J. (2020). Does the COVID-19 outbreak mark the onset of a sustainable consumption transition? Sustainability: Science, Practice, and Policy, 16(1), 1-3. https://doi.org/10.1080/15487733.2020.1740472

Doorley, J., \& Garcia, H. F. (2007). Reputation Management, the Key To Be Successful Public Relations and Corporate Communication.New York: Routledge.

Elkington, J. (2006). Governance for Sustainability. Corporate Governance: An International Review, 14(6), 522-529. https://doi.org/10.1111/j.1467-8683.2006.00527.x

Harapan, H., Itoh, N., Yufika, A., Winardi, W., Keam, S., Te, H., Megawati, D., Hayati, Z., Wagner, A. L., \&Mudatsir, M. (2020). Coronavirus disease 2019 (COVID-19): A literature review. Journal of Infection and Public Health, 13(5), 667-673. https://doi.org/10.1016/j.jiph.2020.03.019

ILO (International Labour Organization). (2020). Asia Pacific Employment and Social Outlook 2020, Navigating the Crisis towards A Human-Centered Future of Work. ISBN 978-92-2-033846-9 (Print), ISBN: 978-92-2-033845-2 (Web PDF). Thailand.
ILO (International Labour Organization). (2021). ILO Monitor: COVID-19 and the World of Work, Seventh Edition, Updated Estimates and Analysis. 25 January 2021.

Jaques, T. (2007). Issue management and crisis management: An integrated, non-linear, relational construct. Public Relations Review, 33(2), 147-157. https://doi.org/10.1016/j.pubrev.2007.02.001

Kniffin, K. M., Narayanan, J., Anseel, F., Antonakis, J., Ashford, S. P., Bakker, A. B., Bamberger, P., Bapuji, H., Bhave, D. P., Choi, V. K., Creary, S. J., Demerouti, E., Flynn, F. J., Gelfand, M. J., Greer, L. L., Johns, G., Kesebir, S., Klein, P. G., Lee, S. Y., ... van Vugt, M. (2020). COVID-19 and the Workplace: Implications, Issues, and Insights for Future Research and Action. American Psychologist. https://doi.org/10.1037/amp0000716

Munasinghe, M. (2004). International Society for Ecological Economics Internet Encyclopaedia of Ecological Economics Sustainomics: A Trans-disciplinary Framework for Making Development More Sustainable. International Society for Ecological Economics, 18.

Petropoulos, F., \&Makridakis, S. (2020). Forecasting the novel coronavirus COVID-19. PLoS ONE, 15(3), 1-8. https://doi.org/10.1371/journal.pone.0231236

Shereen, M. A., Khan, S., Kazmi, A., Bashir, N., \& Siddique, R. (2020). COVID-19 infection: Origin, transmission, and characteristics of human coronaviruses. Journal of Advanced Research, 24, 91-98. https://doi.org/10.1016/j.jare.2020.03.005

Simpson, R. L. (1953). Pitirim Sorokin and his sociology. Social Forces, 32(2), 120-131. https://doi.org/10.2307/2573709

United Nations General Assembly. (2015). Resolution Number A/Res/70/1. Transforming Our World: the 2030 Agenda for Sustainable Development. 15-16301 (E)

Wisnoentoro, R. (2020). The Sustainability of Islamic Finance During A Global Crisis. Islamic Finance News - Special Report, 8th July 2020, V17i27, p.22.

Yi, Y., Lagniton, P. N. P., Ye, S., Li, E., \& Xu, R. H. (2020). COVID-19: What has been learned and to be learned about the novel coronavirus disease. International Journal of Biological Sciences, 16(10), 1753-1766. https://doi.org/10.7150/ijbs.45134 
Zambrano-Monserrate, M. A., Ruano, M. A., \& Sanchez-Alcalde, L. (2020). Indirect effects of COVID-19 on the environment. Science of the Total Environment, 728, 138813. https://doi.org/10.1016/j.scitotenv.2020.138813

\section{List of Other Documents and Websites for Further Readings}

Alphabet Inc. (NASDAQ: GOOG, GOOGL) official report of financial performance 2020 (dated on February 2, 2021)

COVID19.who.int, accessed on 13 March 2021 at 10:38 (JKT); 12 April 2021 at 13:00 (JKT); and 26 April 2021 at 13:45 (JKT)

https://www.npr.org/transcripts/849246712, 4 Mar 2020, accessed on 13 Mar 2021

https://www.history.com/news/spanish-flu-second-wave-resurgen ce, originally written on 3 Mar 2020, updated on 22 Dec 2020, accessed on 13 Mar 2021

https://www.bmj.com/content/372/bmj.n854, (accessed on 17 April 2021; 23:08 Jakarta time)
https://www.ilo.org/asia/media-centre/news/WCMS_763819/lang

--en/index.htm (accessed on 28 April 2021; 13:02 JKT)

https://www.worldbank.org/en/news/press-release/2020/10/07/cov id-19-to-add-as-many-as-150-million-extreme-poor-by-2021 (accessed on 28 April 2021; 13:49 JKT)

https://www.forbes.com/sites/chriswestfall/2020/10/08/mental-he alth-leadership-survey-reveals-80-of-remote-workers-would-quit-t heir-jobs-for-this/?sh=17bc7f243a0f (29 March 2021: 11:00 am $\mathrm{Jkt})$

https://www.cnbc.com/2021/03/01/zoom-zm-earnings-q4-2021.ht $\mathrm{ml}$ (accessed on 26 March 2021; 12:05 pm Jakarta)

https://www.cnbc.com/2021/02/02/alphabet-googl-earnings-q4-20 20.html (accessed on 29 April 2021; 15:38 JKT)

https://instituteforpr.org/issues-management/ (accessed on 30 April 2021; 10:21 JKT)

Citation: Dr. Rizky Wisnoentoro., "The Globe and theCentennial Calamity: A Staggering Reality to Vet Sustainability". American Research Journal of Humanities and Social Sciences, Volume 7, Issue No. 1, 2021, pp. 1-13.

Copyright (C) 2021 Dr. Rizky Wisnoentoro, This is an open access article distributed under the Creative Commons Attribution License, which permits unrestricted use, distribution, and reproduction in any medium, provided the original work is properly cited. 